\title{
Remote Patient Monitoring Technologies for Predicting Chronic Obstructive Pulmonary Disease Exacerbations: Review and Comparison
}

\author{
Kathleen G Fan ${ }^{1}$, BSc; Jess Mandel $^{2}$, MD; Parag Agnihotri ${ }^{3}$, MD; Ming Tai-Seale ${ }^{4}$, MPH, PhD \\ ${ }^{1}$ New York Medical College, Valhalla, CA, United States \\ ${ }^{2}$ Division of Pulmonary, Critical Care, and Sleep Medicine, School of Medicine, University of California San Diego, La Jolla, CA, United States \\ ${ }^{3}$ University of California San Diego Health Population Health Services Organization, University of California San Diego, La Jolla, CA, United States \\ ${ }^{4}$ Department of Family Medicine and Public Health, University of California San Diego, La Jolla, CA, United States
}

Corresponding Author:

Ming Tai-Seale, MPH, PhD

Department of Family Medicine and Public Health

University of California San Diego

9500 Gilman Drive

La Jolla, CA

United States

Phone: 16508155485

Email: mtaiseale@health.ucsd.edu

\section{Abstract}

Background: Chronic obstructive pulmonary disease (COPD) is the third leading cause of death by disease worldwide and has a 30-day readmission rate of 22.6\%. In 2015, COPD was added to the Medicare Hospital Readmission Reductions Program.

Objective: The objective of this paper was to survey the current medical technologies for remote patient monitoring (RPM) tools that forecast COPD exacerbations in order to reduce COPD readmissions.

Methods: We searched literature and digital health news to find commercially available RPM devices focused on predicting COPD exacerbations. These technologies were reviewed and compared according to four criteria: forecasting ability, cost, ease of use, and appearance. A rating system was developed to facilitate the evaluation process.

Results: As of June 2019, a list of handheld and hands-free devices was compiled. We compared features and found substantial variations. Devices that ranked higher on all criteria tended to have a high or unlisted price. Commonly mass-marketed devices like the pulse oximeter and spirometer surprisingly fulfilled the least criteria.

Conclusions: The COPD RPM technologies with most technological promise and compatibility with daily living appear to have high or unlisted prices. Consumers and providers need better access to product information to make informed decisions.

(JMIR Mhealth Uhealth 2020;8(5):e16147) doi: $\underline{10.2196 / 16147}$

\section{KEYWORDS}

COPD; disease exacerbation; remote patient monitoring; mobile health; telehealth; at-home monitoring; remote monitoring system; wearable

\section{Introduction}

Chronic obstructive pulmonary disease (COPD) is the third leading cause of death worldwide and has a 30-day hospital readmission rate of $22.6 \%$ [1,2]. Its exacerbations, if not well managed, can reduce patients' quality of life and increase costs of care [3-6]; COPD is a target condition in the Medicare Hospital Readmission Reductions Program.
Early COPD exacerbation recognition has been a focus of inquiries since faster intervention correlates with better outcomes [7-9]. Oxygen saturation, respiratory rate (RR), and heart rate (HR) have been identified as useful biomarkers [10-14]. Measuring oxygen saturation alone, however, may not be sufficient because it naturally fluctuates throughout the day $[14,15]$. Measuring these biomarkers in the form of remote patient monitoring (RPM) technologies has improved patients' 
abilities to self-manage and decreases COPD's economic and clinical burden $[9,16,17]$.

This paper reviews RPM technologies targeting early COPD exacerbation markers. We provide a concise, practical comparison of technologies to assist consumers and providers in making informed decisions about available technologies.

\section{Methods}

We examined available and commercialized devices by searching for COPD RPM technologies in the literature. We searched Medline and ClinicalTrials.gov and digital health news outlets such as MobiHealthNews, Wearable Technologies, and FierceBiotech with keywords "COPD," "COPD exacerbation," "AECOPD," and "chronic obstructive pulmonary disease" in combinations with "remote patient monitoring," "at-home monitoring," "remote monitoring system," "device," "wearable," and "technology" in June 2019. We narrowed the focus to
FDA-approved devices or ones slated for approval within a year. We grouped selected technologies into handheld versus hands-free devices and compared them using four additional criteria: forecasting ability, cost, ease of use, and appearance. Forecasting ability is the likelihood the device would signal a developing COPD exacerbation based on indicative biomarkers [10-14]. Costs were compared at retail prices, if listed. Ease of use was assessed based on efforts required from users to operate the device because patients are more likely to consistently use passive and user-friendly devices [18-20]. Appearance was considered because it influences user acceptability. Unattractive or uncomfortable devices result in lower take-up [18-20].

Using a star scheme, we rated each device for all criteria besides cost where actual amount (if available) was considered. One star indicates poor fulfillment, three stars indicates adequate fulfillment, and five stars indicates excellent fulfillment of that criterion (Table 1).

Table 1. Comparison of selected chronic obstructive pulmonary disease handheld and hands-free remote monitors.

\begin{tabular}{|c|c|c|c|c|}
\hline Device & Forecasting ability & Cost & Ease of use & Appearance \\
\hline \multicolumn{5}{|l|}{ Handheld } \\
\hline Spirometer & $\star$ & $\$ 99-\$ 2500$ & $\star$ & $\star \star \star$ \\
\hline Pulse oximeter & $\star$ & $\$ 15-\$ 599$ & $\star$ & $\star$ \\
\hline Propeller Health sensor & $\star$ & unlisted & $\star \star \star$ & $\star \star \star$ \\
\hline Cohero Health kit & $\star \star \star$ & $\$ 49 / \mathrm{mo}$ & $\star \star \star$ & $\star \star \star$ \\
\hline \multicolumn{5}{|l|}{ Hands-free } \\
\hline Spry Health Loop System & $\star \star \star \star \star ~$ & unlisted & $\star \star \star \star \star ~$ & 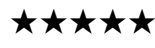 \\
\hline Omron HeartGuide & $\star \star \star$ & $\$ 499$ & $\star \star \star \star \star ~$ & 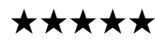 \\
\hline Spire Health Tag & $\star \star \star \star \star ~$ & $\$ 49$ & $\star \star \star$ & $\star \star \star$ \\
\hline Cosinuss One & $\star$ & $\$ 146.50$ & $\star \star \star$ & $\star \star \star$ \\
\hline Current Health Armband & $\star \star \star \star \star ~$ & $\$ 199+\$ 40 / \mathrm{mo}$ & $\star \star \star$ & $\star$ \\
\hline Adamm RSM & $\star \star \star \star \star ~$ & unlisted & $\star \star \star \star \star ~$ & $\star \star \star \star \star \star ~$ \\
\hline
\end{tabular}

\section{Results}

\section{Handheld Monitors}

Spirometers are the gold standard pulmonary function test for COPD diagnosis. With the rise of over-the-counter tabletop to handheld spirometers, at-home spirometry has become common for daily monitoring of the amount and/or speed of air that can be inhaled and exhaled. Spirometers range in cost from a few hundred to several thousand dollars [21,22].

Pulse oximeters are lightweight devices measuring oxygen saturation that have been mass-marketed for at-home care. Pulse oximeters can cost from $\$ 15$ to \$599 [23,24].

The Propeller Health sensor is an electronic inhaler attachment tracking medication use and potential exacerbations $(\geq 10$ inhaler puffs within a 24-hour period or greater usage over a 48-hour period) [25,26]. A study showed 17 of a 39-patient cohort adhered to using the device over a 2-year study [27]. The price of Propeller's asthma sensor is negotiated with health care delivery organizations or payers. It can be free to patients through sponsored health plans but is otherwise around $\$ 300$ [28]. The price of its COPD sensor is not listed.

The Cohero Health kit includes a medical-grade handheld spirometer, medication-tracking sensor, and web app that centralizes the data $[29,30]$. The kit comes as a subscription service for $\$ 49$ per month [31].

\section{Hands-Free Monitors}

Spry Health's Loop System is a wristband monitor. It tracks oxygen saturation, HR, RR, and blood pressure, alerting on significant changes in the wearer's physiological data [32]. Its price is unlisted.

Omron's HeartGuide is a watch-like monitor measuring HR, blood pressure, physical activity, and sleep quality. These features are transmitted to a mobile app where patients can track progress and access health coaching [33]. Although the HeartGuide directly targets patients with heart conditions, its ability to track HR, physical activity, and sleep quality can help detect signs of COPD exacerbation $[34,35]$. The HeartGuide costs \$499. 
The Spire Health Tag is a disposable adhesive sensor that attaches to clothing. Each tag tracks RR, HR, breathing pattern, sleep quality, and physical activity, which are logged into a smartphone app [36]. The tags have a 1-year battery life and are washer and dryer safe. Each tag costs $\$ 49$. Consumers can opt for a Spire membership, which at $\$ 10$ per month provides free replacements and additional tags for $\$ 25$ each [37].

The Cosinuss One is a monitor placed in the ear that connects to a smartphone app to measure HR, HR variability, and body temperature. Cosinuss is currently developing OxMotion, an add-on specific to COPD patients tracking RR and oxygen saturation levels. We primarily discuss Cosinuss One because the OxMotion is not yet available. The Cosinuss One costs $\$ 146.50$ [38].

Current Health's Remotely Monitor system is an armband monitor measuring HR, RR, skin temperature, oxygen saturation, and movement. Data are transmitted to a cloud platform and can be integrated into the patient's electronic health record. At the most basic membership, the Current Armband is \$199 upfront and $\$ 40$ per month for continuous service [39].

The Adamm RSM from Health Care Originals is an adhesive device for the upper torso that monitors cough rate, respiratory patterns, HR, and temperature. Data go to a mobile app and web portal viewable by patients and their physicians [40]. Its price is unlisted.

\section{Discussion}

\section{Principal Findings}

Selected COPD RPM devices were assessed based on forecasting ability, cost, ease of use, and appearance. Spry Health Loop System and Adamm RSM ranked highest across most dimensions aside from cost. The pulse oximeter fulfilled the least criteria.

The Loop System, Current Health Armband, Spire Health Tag, and Adamm RSM ranked highest in forecasting ability since they monitor the most indicative biomarkers. Although Cosinuss One tracks multiple biomarkers, it has shown inaccurate measurements in external studies and thus may not have high forecasting ability [41-43]. Adamm RSM and Spire Health Tag track respiratory patterns, which may be even more accurate [12].

Spirometers, although a well-established COPD diagnostic method, ranked low in forecasting ability. Spirometry, when conducted in outpatient settings or unaided by a health care professional, can often yield inaccurate results due to technical factors [7,44]. Cohero Health's mobile spirometer is International Organization for Standardization (ISO) 9001 and 13485 certified, giving it more accuracy than other mass-marketed spirometers [30]. Although the Propeller sensor is easy to use and has been used to predict incoming exacerbations when it detects increased use of the inhaler, it does not provide data on pulmonary function considered important to predict an incoming exacerbation [27]. Both Cohero and Propeller require patients to use the inhaler, which could face challenges in adherence [18,26].

The Loop System and HeartGuide ranked highest in ease of use. Both devices are wristbands that can be worn without effortful engagement from users to obtain data, which increases usability and adherence [45]. Adamm RSM similarly can be easily hidden under shirts. Other devices with three stars required a little more adjusting. Current Health Armband and pulse oximeter are easy to wear but may shift throughout the day due to their locations on the arm and finger, respectively.

Although relatively easy to use, the Current Health Armband ranked lowest in appearance due to its bulky design and high-profile arm placement. Pulse oximeters also ranked low due to high visibility. While patients can choose to spot check rather than continuously wear the device, this would require some reminder, therefore decreasing its ease of use.

Other devices were relatively low profile. The Loop and HeartGuide are modeled after watches while the handheld spirometer and Propeller inhaler can be carried in a pocket or bag. The Spire Health Tag is out of view once attached to clothing. Adherence becomes challenged if consumers change or discard clothing with the Health Tag attached, however. The Cosinuss One is a low-profile earpiece but may be disadvantageous because it may impede hearing.

Cost-wise, the Spire Health Tag seemingly ranks lowest. But because the sensor may only be attached once, users must decide which clothing they wear most frequently and wear those items every day. Over-the-counter options such as spirometers and pulse oximeters, although inexpensive compared to other RPM devices, are often inaccurate in measurement and have less robust premarket testing $[7,46]$.

\section{Limitations}

This review is not exhaustive. It provides a review of devices currently on the market and readily searchable online. Some technologies were not selected because they were similar in function but not yet on the market or lacked product information. Future efforts are necessary to update this review, given digital health technology is continually improving and evidence for efficacy of RPM in reducing COPD exacerbations is still developing [47]. Another limitation concerns the star rating system, which is based on qualitative assessments rather than quantitative metrics [47]. Last, technology is only one aspect of COPD management strategy. More guideline-concordant treatment and better patient engagement are needed, but they are beyond the scope of this brief report [48].

\section{Conclusion}

Patients can better manage their COPD with the aid of RPM technology that can be easily adopted into their daily routine. The most promising devices are either expensive or without available cost information. Consumers and health care organizations can benefit from more publicly accessible information on COPD RPM products and their comparative effectiveness and costs. 


\section{Conflicts of Interest}

None declared.

\section{References}

1. World Health Organization. 2018 May 24. The top 10 causes of death URL: https://www.who.int/news-room/fact-sheets/ detail/the-top-10-causes-of-death [accessed 2020-04-13]

2. Shah T, Press VG, Huisingh-Scheetz M, White SR. COPD readmissions: addressing COPD in the era of value-based health care. Chest 2016 Oct;150(4):916-926 [FREE Full text] [doi: 10.1016/j.chest.2016.05.002] [Medline: 27167208]

3. McIlvennan CK, Eapen ZJ, Allen LA. Hospital readmissions reduction program. Circulation 2015 May 19;131(20):1796-1803 [FREE Full text] [doi: 10.1161/CIRCULATIONAHA.114.010270] [Medline: 25986448]

4. Blanchette CM, Gross NJ, Altman P. Rising costs of COPD and the potential for maintenance therapy to slow the trend. Am Health Drug Benefits 2014 Apr;7(2):98-106 [FREE Full text] [Medline: 24991394]

5. Goto T, Faridi MK, Gibo K, Toh S, Hanania NA, Camargo CA, et al. Trends in 30-day readmission rates after COPD hospitalization, 2006-2012. Respir Med 2017 Sep;130:92-97 [FREE Full text] [doi: 10.1016/j.rmed.2017.07.058] [Medline: $\underline{29206640]}$

6. Wilkinson TMA, Donaldson GC, Hurst JR, Seemungal TAR, Wedzicha JA. Early therapy improves outcomes of exacerbations of chronic obstructive pulmonary disease. Am J Respir Crit Care Med 2004 Jun 15;169(12):1298-1303. [doi: 10.1164/rccm.200310-14430C] [Medline: 14990395]

7. Liistro G, Vanwelde C, Vincken W, Vandevoorde J, Verleden G, Buffels J, COPD Advisory Board. Technical and functional assessment of 10 office spirometers: a multicenter comparative study. Chest 2006 Sep;130(3):657-665. [doi: 10.1378/chest.130.3.657] [Medline: 16963659 ]

8. Borel J, Pelletier J, Taleux N, Briault A, Arnol N, Pison C, et al. Parameters recorded by software of non-invasive ventilators predict COPD exacerbation: a proof-of-concept study. Thorax 2015 Mar;70(3):284-285. [doi: 10.1136/thoraxjnl-2014-206569] [Medline: 25582449]

9. Hurst JR, Skolnik N, Hansen GJ, Anzueto A, Donaldson GC, Dransfield MT, et al. Understanding the impact of chronic obstructive pulmonary disease exacerbations on patient health and quality of life. Eur J Intern Med 2020 Jan 16 [FREE Full text] [doi: 10.1016/j.ejim.2019.12.014] [Medline: 31954592]

10. Shah SA, Velardo C, Farmer A, Tarassenko L. Exacerbations in chronic obstructive pulmonary disease: identification and prediction using a digital health system. J Med Internet Res 2017 Mar 07;19(3):e69 [FREE Full text] [doi: 10.2196/jmir.7207] [Medline: 28270380]

11. Yañez AM, Guerrero D, Pérez DAR, Garcia-Rio F, Alvarez-Sala JL, Calle-Rubio M, et al. Monitoring breathing rate at home allows early identification of COPD exacerbations. Chest 2012 Dec;142(6):1524-1529. [doi: 10.1378/chest.11-2728] [Medline: 22797131]

12. Blouet S, Sutter J, Fresnel E, Kerfourn A, Cuvelier A, Patout M. Prediction of severe acute exacerbation using changes in breathing pattern of COPD patients on home noninvasive ventilation. Int J Chron Obstruct Pulmon Dis 2018;13:2577-2586 [FREE Full text] [doi: 10.2147/COPD.S170242] [Medline: $\underline{\text { 30214176] }}$

13. Al Rajeh AM, Hurst JR. Monitoring of physiological parameters to predict exacerbations of chronic obstructive pulmonary disease (COPD): a systematic review. J Clin Med 2016 Nov 25;5(12):108 [FREE Full text] [doi: 10.3390/jcm5120108] [Medline: 27897995]

14. Tomasic I, Tomasic N, Trobec R, Krpan M, Kelava T. Continuous remote monitoring of COPD patients: justification and explanation of the requirements and a survey of the available technologies. Med Biol Eng Comput 2018 Apr;56(4):547-569 [FREE Full text] [doi: 10.1007/s11517-018-1798-z] [Medline: 29504070]

15. Buekers J, Theunis J, De Boever P, Vaes AW, Koopman M, Janssen EV, et al. Wearable finger pulse oximetry for continuous oxygen saturation measurements during daily home routines of patients with chronic obstructive pulmonary disease (COPD) over one week: observational study. JMIR Mhealth Uhealth 2019 Jun 06;7(6):e12866 [FREE Full text] [doi: 10.2196/12866] [Medline: 31199331]

16. Vegesna A, Tran M, Angelaccio M, Arcona S. Remote patient monitoring via non-invasive digital technologies: a systematic review. Telemed J E Health 2017 Jan;23(1):3-17 [FREE Full text] [doi: 10.1089/tmj.2016.0051] [Medline: 27116181]

17. Guarascio AJ, Ray SM, Finch CK, Self TH. The clinical and economic burden of chronic obstructive pulmonary disease in the USA. Clinicoecon Outcomes Res 2013;5:235-245 [FREE Full text] [doi: 10.2147/CEOR.S34321] [Medline: 23818799]

18. Lazar A. Why we use and abandon smart devices. 2015 Presented at: Proceedings of the ACM International Joint Conference on Pervasive and Ubiquitous Computing; 2015; Osaka. [doi: 10.1145/2750858.2804288]

19. Lee J, Kim D, Ryoo H, Shin B. Sustainable wearables: wearable technology for enhancing the quality of human life. Sustainability 2016 May 11;8(5):466. [doi: 10.3390/su8050466]

20. Hermsen S, Moons J, Kerkhof P, Wiekens C. Determinants for sustained use of an activity tracker: observational study. JMIR Mhealth Uhealth 2017 Oct 30;5(10):e164 [FREE Full text] [doi: 10.2196/mhealth.7311] [Medline: 29084709]

21. Medical Device Depot. MIR SmartOne Portable Spirometer URL: https://www.medicaldevicedepot.com/ MIR-SmartOne-Portable-Spirometer-p/SmartOne.htm [accessed 2020-04-13] 
22. CardiacDirect. MIR SpiroLab Light Spirometer URL: https://www.cardiacdirect.com/Category/spirometers-1.html [accessed 2020-04-13]

23. FL400 Fingertip Pulse Oximeter. URL: https://www.pulseoximeter.org/fl400-black.html [accessed 2020-04-13]

24. CardiacDirect. DPM 2 Pulse Oximeter with Charging Stand and Rechargeable Battery URL: https://www.cardiacdirect.com/ Product/DPM-2-Pulse-Oximeter-with-Charging-Stand-and-Rechargeable-Battery.html [accessed 2020-04-13]

25. Propeller Health. URL: https://www.propellerhealth.com/ [accessed 2020-04-13]

26. Chen J, Kaye L, Tuffli M, Barrett MA, Jones-Ford S, Shenouda T, et al. Passive monitoring of short-acting beta-agonist use via digital platform in patients with chronic obstructive pulmonary disease: quality improvement retrospective analysis. JMIR Form Res 2019 Oct 23;3(4):e13286 [FREE Full text] [doi: 10.2196/13286] [Medline: $\underline{31647471]}$

27. Alshabani K, Attaway AA, Smith MJ, Majumdar U, Rice R, Han X, et al. Electronic inhaler monitoring and healthcare utilization in chronic obstructive pulmonary disease. J Telemed Telecare 2019 May 16:1357633X19850404. [doi:

10.1177/1357633X19850404] [Medline: $\underline{31096842]}$

28. Wagner A. PBS NewsHour. 2017 May 10. Asthma patients breathe easier with new bluetooth inhalers URL: https://www. pbs.org/newshour/health/asthma-patients-breathe-easier-new-bluetooth-inhalers [accessed 2020-04-13]

29. Cohero Health. URL: https://coherohealth.com/ [accessed 2020-04-13]

30. Melvin E, Cushing A, Tam A, Kitada R, Manice M. Assessing the use of BreatheSmart® mobile technology in adult patients with asthma: a remote observational study. BMJ Open Respir Res 2017;4(1):e000204 [FREE Full text] [doi:

10.1136/bmjresp-2017-000204] [Medline: 29071077]

31. Dickey, MR. TechCrunch. 2015 Sep 21. Cohero Health aims to improve patient care for the 26 million american asthma sufferers URL: https://tinyurl.com/y9z9w8pr [accessed 2020-04-13]

32. Spry Health. URL: https://spryhealth.com/ [accessed 2020-04-13]

33. Omron Health HeartGuide. 2019 Jun 21. URL: https://tinyurl.com/yab663sx [accessed 2020-04-13]

34. Garcia-Rio F, Rojo B, Casitas R, Lores V, Madero R, Romero D, et al. Prognostic value of the objective measurement of daily physical activity in patients with COPD. Chest 2012 Aug;142(2):338-346. [doi: 10.1378/chest.11-2014] [Medline: 22281798]

35. Shorofsky M, Bourbeau J, Kimoff J, Jen R, Malhotra A, Ayas N, Canadian Respiratory Research Network, CanCOLD Collaborative Research group. Impaired sleep quality in COPD is associated with exacerbations: the CanCOLD Cohort Study. Chest 2019 Nov;156(5):852-863. [doi: 10.1016/j.chest.2019.04.132] [Medline: 31150638]

36. Holt M, Yule B. Ambulatory monitoring of respiratory effort using a clothing-adhered biosensor. 2018 Presented at: Proceedings of the IEEE International Symposium on Medical Measurements and Applications; 2018; Rome p. 1-6. [doi: 10.1109/memea.2018.8438678]

37. SpireHealth. URL: https://spirehealth.com/ [accessed 2020-04-13]

38. Cosinuss One. URL: https://www.cosinuss.com/ [accessed 2020-04-13]

39. Current Health. URL: https://currenthealth.com/ [accessed 2020-04-13]

40. Health Care Originals. Adamm RSM URL: http://healthcareoriginals.com/solutions/\#adamm-rsm [accessed 2020-04-13]

41. Roossien CC, Heus R, Reneman MF, Verkerke GJ. Monitoring core temperature of firefighters to validate a wearable non-invasive core thermometer in different types of protective clothing: concurrent in-vivo validation. Appl Ergon 2020 Feb;83:103001. [doi: 10.1016/j.apergo.2019.103001] [Medline: 31739139]

42. Passler S, Müller N, Senner V. In-ear pulse rate measurement: a valid alternative to heart rate derived from electrocardiography? Sensors (Basel) 2019 Aug 21;19(17):3641 [FREE Full text] [doi: 10.3390/s19173641] [Medline: $\underline{31438600]}$

43. Chaglla ES, Celik N, Balachandran W. Measurement of core body temperature using graphene-inked infrared thermopile sensor. Sensors (Basel) 2018 Oct 03;18(10):3315 [FREE Full text] [doi: 10.3390/s18103315] [Medline: 30282932]

44. Hegewald MJ, Gallo HM, Wilson EL. Accuracy and quality of spirometry in primary care offices. Ann Am Thorac Soc 2016 Dec;13(12):2119-2124. [doi: 10.1513/AnnalsATS.201605-4180C] [Medline: 27598295]

45. Cornet VP, Holden RJ. Systematic review of smartphone-based passive sensing for health and wellbeing. J Biomed Inform 2018 Jan;77:120-132. [doi: 10.1016/j.jbi.2017.12.008] [Medline: 29248628]

46. Lipnick MS, Feiner JR, Au P, Bernstein M, Bickler PE. The accuracy of 6 inexpensive pulse oximeters not cleared by the Food and Drug Administration: the possible global public health implications. Anesth Analg 2016 Aug;123(2):338-345. [doi: 10.1213/ANE.0000000000001300] [Medline: 27089002]

47. Walker PP, Pompilio PP, Zanaboni P, Bergmo TS, Prikk K, Malinovschi A, et al. Telemonitoring in chronic obstructive pulmonary disease (CHROMED): a randomized clinical trial. Am J Respir Crit Care Med 2018 Sep 01;198(5):620-628. [doi: 10.1164/rccm.201712-24040C] [Medline: 29557669]

48. Ghosh S, Anderson WH, Putcha N, Han MK, Curtis JL, Criner GJ, Current and former investigators of the SPIROMICS sites and reading centers. Alignment of inhaled chronic obstructive pulmonary disease therapies with published strategies. analysis of the global initiative for chronic obstructive lung disease recommendations in SPIROMICS. Ann Am Thorac Soc 2019 Feb;16(2):200-208. [doi: 10.1513/AnnalsATS.201804-2830C] [Medline: 30216731] 


\begin{abstract}
Abbreviations
COPD: chronic obstructive pulmonary disease

HR: heart rate

ISO: International Organization for Standardization

RPM: remote patient monitoring

RR: respiratory rate
\end{abstract}

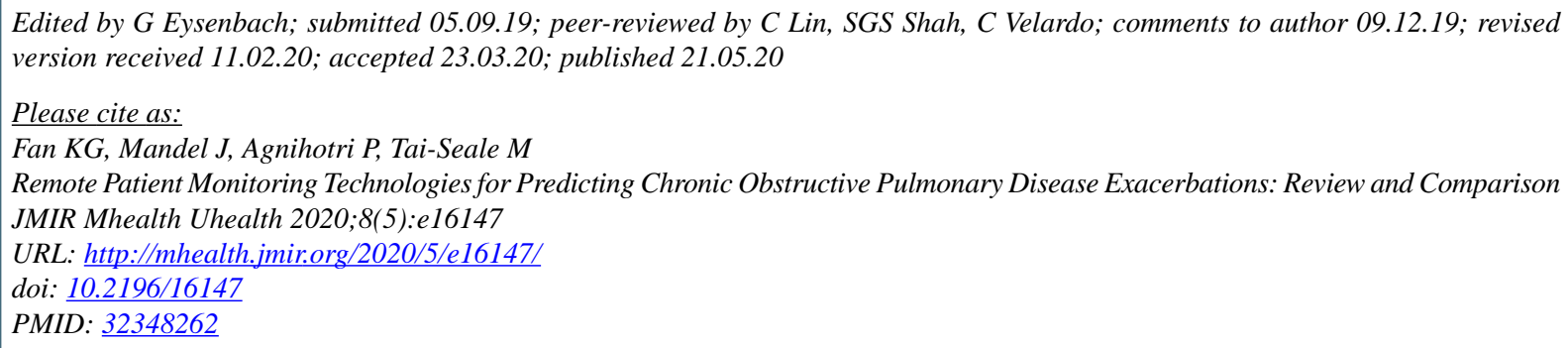

CKathleen G Fan, Jess Mandel, Parag Agnihotri, Ming Tai-Seale. Originally published in JMIR mHealth and uHealth (http://mhealth.jmir.org), 21.05.2020. This is an open-access article distributed under the terms of the Creative Commons Attribution License (https://creativecommons.org/licenses/by/4.0/), which permits unrestricted use, distribution, and reproduction in any medium, provided the original work, first published in JMIR mHealth and uHealth, is properly cited. The complete bibliographic information, a link to the original publication on http://mhealth.jmir.org/, as well as this copyright and license information must be included. 